\title{
Type IIb diamonds originate from the sublithospheric mantle
}

\author{
Evan. M. Smith and Wuyi Wang \\ Gemological Institute of America, New York, USA, evan.smith@gia.edu
}

Introduction

Type IIb diamonds, those defined as having trace amounts of substitutional boron, are prized for their blue colors. The famous Hope diamond is a perfect example. Besides their boron content, these rare diamonds are also characterized by their general lack of nitrogen. Little is known about how type IIb diamonds form, but they are especially intriguing because boron is often regarded as a crustal element whose presence in mantle-derived diamonds is unexpected.

Despite interest in type IIb diamonds as a potential geochemical tracer of mantle processes, minimal research progress has been made to date. They are simply so rare and their color so highly valued that sample access is problematic. Even when access to type IIb diamonds is granted, these diamonds are typically free of mineral or fluid inclusions that might illuminate their geological significance (e.g. Gaillou et al. 2012; King et al. 1998).

\section{Methods}

To investigate the geology of type IIb diamonds, we leveraged the day-to-day diamond grading operations of the Gemological Institute of America. Diamonds passing through GIA's New York laboratory were systematically screened to identify type IIb diamonds with inclusions. Over the course of about a year, more than twenty prospective diamonds were encountered. Each prospective diamond was then carefully examined and inclusions were analyzed using laser Raman spectroscopy in order to identify included mineral phases in-situ, nondestructively. Polished diamonds are well suited to Raman analysis because they are covered on all sides by high quality windows that permit optical access to most of internal space within the diamond. Most inclusions could be characterized this way, relatively quickly and without disrupting the flow of diamond grading. This approach allowed the examination of multiple examples of what are otherwise exceedingly rare and inaccessible diamonds.

\section{Results and Discussion}

The most common inclusion identified in the type IIb diamonds examined was $\mathrm{CaSiO}_{3}$-walstromite, interpreted as an inversion product from $\mathrm{CaSiO}_{3}$-perovskite. Some of these inclusions also contained larnite $\left(\mathrm{Ca}_{2} \mathrm{SiO}_{4}\right)$, and less frequently $\mathrm{CaSi}_{2} \mathrm{O}_{5}$-titanite, wollastonite, and perovskite $\left(\mathrm{CaTiO}_{3}\right)$. The second most common inclusion type was pyroxene, with some inclusions also containing jeffbenite (TAPP), spinel and olivine. These inclusions are interpreted as retrogressed bridgmanite $\left(\mathrm{MgSiO}_{3}-\right.$ perovskite). An important additional inclusion phase found in three diamonds is coesite, interpreted as inverted stishovite. These assemblages suggest derivation from a basic, possibly Ca-rich, host rock paragenesis from the lower mantle.

As shown in figure 1 , the silicate inclusions are often surrounded by graphitic decompression fractures and lobate sprays of tiny satellite inclusions in healed fractures emanating from the main inclusion. These satellite inclusions probably formed during decompression, as the inclusion ruptured the host diamond and some of the inclusion expanded out into the fracture, followed by healing of the crack. Such behaviour requires significant inclusion volume expansion, consistent with a deep, sublithospheric origin for the inclusions. Equivalent inclusion textures have been described previously from sublithospheric diamonds (Smith et al. 2016). 

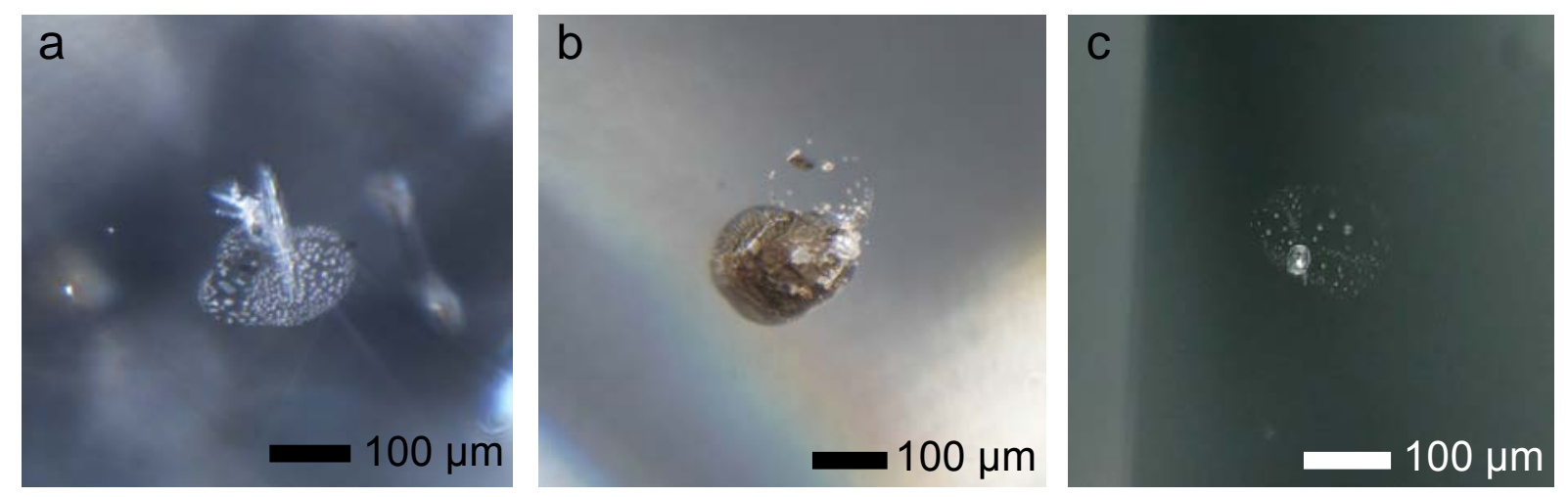

Figure 1: Examples of high-pressure silicate inclusions residing inside several cut and polished type IIb diamonds. a, b) Inclusions of colorless transparent calcium-silicate phases, dominated by $\mathrm{CaSiO}_{3}$-walstromite, interpretted as former $\mathrm{CaSiO}_{3}$-perovskite. c) Inclusion of orthopyroxene, interpretted as former bridgmanite.

The implication that type IIb diamonds originate from the sublithospheric mantle is surprising, but follows suit with the recent findings that many large, predominantly type IIa diamonds like the 3106 carat Cullinan (CLIPPIR diamonds) likely come from the mantle transition zone and also contain silicate inclusions of basic affinity (Smith et al. 2016). These findings show that some of the most prized of all diamonds are also invaluable samples of the deep Earth.

\section{References}

Gaillou E, Post JE, Rost D, Butler JE (2012) Boron in natural type IIb blue diamonds: Chemical and spectroscopic measurements. Am Mineral 97(1):1-18

King JM, Moses TM, Shigley JE, Welbourn CM, Lawson SC, Cooper M (1998) Characterizing natural-color type IIb blue diamonds. Gems \& Gemology 34(4):246-268

Smith EM, Shirey SB, Nestola F, Bullock ES, Wang J, Richardson SH, Wang W (2016) Large gem diamonds from metallic liquid in Earth's deep mantle. Science 354(6318):1403-1405 doi:10.1126/science.aal1303 